\title{
MODELAGEM MOLECULAR: UMA FERRAMENTA PARA O PLANEJAMENTO RACIONAL DE FÁRMACOS EM QUÍMICA MEDICINAL ${ }^{1}$
}

Eliezer J. Barreiro* \& Carlos Rangel Rodrigues

DTF - Faculdade de Farmácia - Universidade Federal do Rio de Janeiro - CP 68006 21944-390 - Rio de Janeiro - RJ Magaly Girão Albuquerque, Carlos Mauricio Rabello de Sant'Anna \& Ricardo Bicca de Alencastro

Departamento de Química Orgânica - Instituto de Química - Universidade Federal do Rio de Janeiro - Cidade Universitária, CT, B1. A - Lab. 622 - 21949-900 - Rio de Janeiro - RJ

Recebido em 18/4/96; aceito em 19/9/96

\begin{abstract}
MOLECULAR MODELING: A TOOL FOR RATIONAL DRUG DESIGN IN MEDICINAL CHEMISTRY. The molecular basis of modern therapeutics consist in the modulation of cell function by the interaction of microbioactive molecules as drug cells macromolecules structures. Molecular modeling is a computational technique developed to access the chemical structure. This methodology, by means of the molecular similarity and complementary paradigm, is the basis for the computer-assisted drug design universally employed in pharmaceutical research laboratories to obtain more efficient, more selective, and safer drugs. In this work, we discuss some methods for molecular modeling and some approaches to evaluate new bioactive structures in development by our research group.
\end{abstract}

KEYWORDS: molecular modeling; medicinal chemistry; drug design.

\section{INTRODUÇÃO}

Em nenhuma outra área da Química, o conhecimento completo da estrutura molecular é tão essencial como na Química Medicinal. Esta disciplina das Ciências Farmacêuticas estuda as origens moleculares da atividade biológica dos fármacos, determinando os parâmetros que relacionam estrutura e atividade e aplicando estes fundamentos no planejamento racional dos fármacos ${ }^{2}$.

As teorias desenvolvidas para explicar a atividade farmacológica das drogas sustentam-se, numa primeira aproximação, no paradigma da "chave-fechadura" "fechaduras" ou receptores celulares são biomacromoléculas de extrema sensibilidade, responsáveis pelo reconhecimento molecular de espécies endógenas e exógenas capazes de apresentar atividade biológica. Estes receptores interagem reversivelmente, em geral, com as moléculas bioativas (mediadores celulares endógenos e fármacos), consideradas neste modelo como as "chaves".

Os complexos formados entre as moléculas bioativas e os receptores provocam as respostas biológicas e dependem de um mecanismo de reconhecimento molecular que determina a seletividade dos bioreceptores. O padrão de seletividade é a expressão do reconhecimento à nível molecular de apenas uma substância dentre os inúmeros compostos estruturalmente relacionados disponíveis na biofase.

A propriedade de reconhecimento molecular depende essencialmente da estrutura química e, em última análise, determina a atividade farmacológica de uma substância ${ }^{2}$. Muitas vezes, um bioreceptor apresenta enantioespecificidade, ou seja, reconhece apenas um dos enantiômeros de uma substância quiral. Este isômero bioativo é denominado eutômero. $\mathrm{O}$ outro enantiômero, que não é reconhecido pelo bioreceptor, é chamado distômero ${ }^{3,4}$. Esta situação é talvez o exemplo mais notável da especificidade das interações droga-receptor e de sua dependência das relações estruturais ${ }^{4,5}$.

A nível experimental, o conhecimento da estrutura molecular de uma substância não é tarefa simples. Não são muitos os métodos capazes de caracterizar completamente uma dada estrutura, permitindo sua descrição precisa em termos de distâncias e ângulos de ligação, além de ângulos de torção (ou ângulos diedro) que difinem sua conformação. A cristalografia de raios- $\mathrm{X}^{6-8}$ é, ainda, a técnica experimental mais eficiente para a obtenção destes dados. Limita-se, todavia, a substâncias em fase cristalina. Além disto, não há garantia de que a conformação no estado cristalino seja a mesma das moléculas em solução ${ }^{6,9}$, ou ainda a geometria assumida no complexo droga-receptor na biofase.

Dentro deste contexto, a modelagem da estrutura molecular por métodos computacionais surgiu como uma alternativa, especialmente após o desenvolvimento de programas capazes de calcular a estrutura com um compromisso adequado entre velocidade e precisão, somados aos recursos da computação gráfica e à crescente diminuição dos custos de máquinas de alto desempenho capazes de operar estes programas e recursos ${ }^{10}$.

A modelagem molecular consiste em um conjunto de ferramentas para a construção, edição e visualização, análise e armazenamento de sistemas moleculares complexos ${ }^{2,5}$. Estas ferramentas podem ser aplicadas em estratégias de modelagem direta e indireta de novas drogas ${ }^{2}$. Na primeira aproximação, faz-se o ajuste da droga a uma estrutura de receptor conhecida, por exemplo, através de dados de cristalografia de raios- $\mathrm{X}^{6,7}$ ou de ressonância magnética nuclear $(\mathrm{RMN})^{11,12}$. Na segunda aproximação, faz-se a análise comparativa das estruturas de moléculas ativas e de moléculas inativas ao nível de um determinado bioreceptor, utilizando-se o conceito de complementaridade para o desenvolvimento de um modelo topográfico hipotético do sítio receptor, denominado modelo farmacofórico.

Existem muitas opções quanto ao método de cálculo a ser aplicado em uma determinada estratégia de modelagem molecular. Estes métodos basicamente diferem quanto à natureza do campo de força, ou seja, do conjunto de funções de energia e parâmetros numéricos associados. Os campos podem ser totalmente empíricos, como os utilizados em mecânica molecular, ou, no outro extremo, puramente teóricos (métodos $a b$ initio), passando pelos chamados métodos semi-empíricos. A aplicação de um ou outro método é determinada pelo compromisso entre tempo e precisão dos resultados e pela complexidade do sistema a ser analisado ${ }^{2}$.

Neste trabalho serão discutidos, brevemente, alguns métodos 
e metodologias empregados em modelagem molecular e alguns exemplos de abordagens feitas pelo nosso grupo de pesquisa para avaliar e definir novas estruturas bioativas em desenvolvimento no Laboratório de Avaliação e Síntese de Substâncias Bioativas (LASSBio).

Métodos de cálculo utilizados em Modelagem Molecular

$\mathrm{O}$ método da mecânica molecular ${ }^{13}$ baseia-se na visão clássica da estrutura molecular como um conjunto de esferas unidas por molas com constantes de força características. O campo de forças neste caso é constituído pelo somatório de termos de energia relacionados às posições de equilíbrio do sistema (distâncias de ligação, ângulos de ligação, ângulos diedros, distâncias de van der Waals, ligações hidrogênio, interações eletrostáticas, etc.) às quais podem ser associadas penalidades energéticas para seu afastamento, isto é, as constantes de força das "molas". Em geral, estas constantes de força são avaliadas por meio de dados espectroscópicos. A principal vantagem da mecânica molecular é a rapidez na avaliação de sistemas moleculares complexos.

Os pacotes de programas de mecânica molecular (AMBER, CHARM, DISCOVER, MM2/MMP2, PCMODEL-MMX, SYBIL, etc.) utilizam diferentes funções de energia potencial para representar a energia interna de uma molécula ${ }^{7,14,15}$. O campo de força AMBER (Assisted Model Building with Energy Refinement), por exemplo, é expresso pela equação $(1)^{15}$ :

$$
\begin{aligned}
& \mathrm{E}_{\text {total }}=\Sigma_{\text {ligaçăo }} \mathrm{k}_{\mathrm{r}}\left(\mathrm{r}-\mathrm{r}_{0}\right)^{2}+\Sigma_{\text {ângulo }} \mathrm{k}_{\theta}\left(\theta-\theta_{0}\right)^{2}+\Sigma_{\text {diedro }} \mathrm{k}_{\phi} / 2 \\
& (1+\mathrm{s} \cdot \cos \mathrm{n} \phi)+\Sigma_{\mathrm{i}<\mathrm{j}}\left(\mathrm{a}_{\mathrm{ij}} / \mathrm{r}_{\mathrm{ij}}{ }^{12}-\mathrm{b}_{\mathrm{ij}} / \mathrm{r}_{\mathrm{ij}}{ }^{6}+\mathrm{q}_{\mathrm{i}} \mathrm{q}_{\mathrm{j}} / \mathrm{D} \cdot \mathrm{r}_{\mathrm{ij}}\right)+\Sigma_{\text {ligaçăo-H }} \\
& \left(\mathrm{c}_{\mathrm{ij}} / \mathrm{r}_{\mathrm{ij}}{ }^{12}-\mathrm{d}_{\mathrm{ij}} / \mathrm{r}_{\mathrm{ij}}{ }^{10}\right)
\end{aligned}
$$

em que os três primeiros termos representam, respectivamente, as energias de deformação dos comprimentos e ângulos de ligação e ângulos diedro, dentro da aproximação harmônica; o quarto termo corresponde à energia das interações não ligantes (London) e eletrostáticas (Coulomb); e o quinto termo representa as contribuições de ligações hidrogênio ${ }^{13,15,16}$.

Outros exemplos são o campo de força MM2, muito utilizado para moléculas de baixo peso molecular, desenvolvido por Allinger ${ }^{13}$ e o campo de força MMX, contido no programa PCMODEL, sendo derivado do campo MM2, acrescido de rotinas $\pi$-VESCF (Valence Electron Self-Consistent Field) para cálculos de sistemas $\pi$.

Os métodos de mecânica quântica ${ }^{14,17}$, por outro lado, permitem maior precisão nos resultados, além de fornecerem dados sobre a estrutura eletrônica, que não é considerada na mecânica molecular. Isto implica em um custo computacional (tempo de computação e capacidade de memória necessária) maior.

Os pacotes de programas de métodos quânticos $a b$ initio (CADPAC, GAMESS, GAUSSIAN, HONDO, etc.) e semiempíricos (AMPAC, MOPAC, etc.) são baseados no formalismo de orbitais moleculares com diferentes abordagens ${ }^{7,14,15}$. Nos métodos ab initio, um modelo para uma função de onda particular é selecionado e os cálculos necessários são realizados sem simplificação. Em tais abordagens o erro está associado ao conjunto de bases selecionado e ao nível de tratamento da correlação eletrônica ${ }^{18}$.

Os métodos semi-empíricos são baseados no mesmo formalismo dos métodos $a b$ initio, mas parte de seus parâmetros são ajustados a dados experimentais. A parametrização dos métodos semi-empíricos com dados experimentais aumentou significativamente a acuracidade química e a velocidade dos métodos de orbitais moleculares. O sucesso desta abordagem é indicado por inúmeros estudos mostrando dados energéticos que variam na faixa de $1,0 \mathrm{kcal} / \mathrm{mol}$ dos dados experimentais ${ }^{15}$. Os métodos semi-empíricos mais recentes são AM1 (Austin Model 1) ${ }^{19}$ e PM3 (Parametric Method 3) ${ }^{20,21}$, contidos nos pacotes AMPAC e MOPAC. Do ponto de vista da estrutura das liga- ções hidrogênio, importantes em sistemas biológicos, o método PM3 tem apresentado resultados mais próximos aos obtidos experimentalmente e por cálculos ab initio ${ }^{22-24}$.

As diversas aproximações semi-empíricas permitem evitar o cálculo de um grande número de integrais, o que possibilita a aplicação destes métodos em sistemas com um número maior de átomos. Nestes métodos, os núcleos são assumidos em sucessivas posições estacionárias, sobre as quais a distribuição espacial ótima dos elétrons é calculada pela resolução da equação de Schrödinger. O processo é repetido até que a energia não mais varie dentro de um limite escolhido, ou seja, até se alcançar um ponto estacionário da superfície de energia. Esta procura por um estado estacionário da geometria calculada no espaço multidimensional é o equivalente computacional da purificação experimental de uma amostra antes de se avaliar suas características físico-químicas.

Em um sistema no estado fundamental, isto significa que a geometria é tal que o calor de formação $\left(\Delta \mathrm{H}_{\mathrm{f}}\right)$ é um mínimo irredutível (na verdade um mínimo irredutível local), ou seja, todas as suas constantes de força são positivas; para estados de transição, o sistema deve ter exatamente uma constante de força negativa ${ }^{25,26}$. Deste modo, tem se tornado prática comum nos trabalhos teóricos de qualidade, a avaliação de todas as segundas derivadas (constantes de força) da energia molecular em função dos parâmetros moleculares, para se determinar inequivocamente a natureza dos pontos estacionários encontrados no processo de otimização da geometria da estrutura ${ }^{25}$.

\section{METODOLOGIAS E PARÂMETROS USADOS EM MODELAGEM MOLECULAR}

A modelagem de uma estrutura permite isolá-la e "congelála". Estruturas com tempos de vida muito curtos, tais como intermediários de reação ou estados de transição hipotéticos podem ser modelados e suas propriedades "medidas" com relativa facilidade ${ }^{14,27}$. A possibilidade do estudo das conformações e propriedades de uma molécula isolada, simulando o estado gasoso, ou da molécula solvatada, ainda que por um número pequeno de moléculas de solvente, permite predizer as conformações preferenciais em cada caso particular.

Em muitos casos, dados experimentais de espectroscopia de microondas podem ser utilizados para comparação com os dados calculados para a molécula isolada. Dados de difração de raios-X e de difração de nêutrons podem também ser empregados, desde que se considere as forças de empacotamento cristalino. Estudos espectroscópicos de RMN e de infravermelho (FTIR) em solução, podem ser também comparados com os dados calculados para a molécula solvatada, desde que se mantenham certas propriedades características do solvente, como por exemplo, a capacidade de formar ligação hidrogênio e a constante dielétrica. Exemplos nesse sentido são, dentre outros, os programas computacionais capazes de simular a solvatação ${ }^{28}$, ou os que fornecem bancos de dados de estruturas tridimensionais de moléculas que possuem os requerimentos estruturais exigidos para que se observe uma determinada bioatividade ${ }^{29,30}$.

Além de fornecer dados estruturais, os cálculos teóricos são usados também na computação de índices de interesse químico e farmacológico, tais como: calores de formação, energias eletrônicas, energias do HOMO (Highest Occupied Molecular Orbital) e do LUMO (Lowest Unoccupied Molecular Orbital), energias de ionização, densidades eletrônicas atômicas, cargas atômicas líquidas, densidades eletrônicas dos orbitais de fronteira (HOMO e LUMO), ordens de ligação e momentos de dipolo, entre outros ${ }^{2,31}$. Dentre estes parâmetros, as energias do HOMO e do LUMO estão correlacionadas às habilidades de doador e aceptor de elétron, respectivamente. Uma maior energia do HOMO está correlacionada com uma maior probabilidade de doar elétrons, enquanto que uma menor energia do LUMO está 
relacionada a uma maior facilidade em aceitar elétrons ${ }^{31,32}$

Expressões como CADD (Computer Aided Drug Design, desenho de drogas assistido computacionalmente), entre outras, foram recentemente incorporadas à linguagem da Química Medicinal. Trata-se de uma metodologia que visa determinar distâncias interatômicas e densidades eletrônicas de moléculas de interesse biológico, estudar o equilíbrio conformacional das biomoléculas definindo as conformações potencialmente bioativas, explicar racionalmente as atividades farmacológicas de substâncias e definir, confirmar ou descartar hipóteses para o mecanismo de ação a nível eletrônico e molecular de diversos fármacos e, finalmente, identificar interações específicas entre drogas e receptores, definindo os grupamentos farmacofóricos ${ }^{33,34}$.

É possível definir, ainda, hipóteses topográficas para sítios receptores de diversas classes de drogas, deduzindo tridimensionalmente a interação molecular de uma determinada droga e seu receptor, modelando biomacromoléculas-alvo (sítios ativos de enzimas, de receptores e de ácidos nucleicos; ou enzimas, receptores e ácidos nucléicos íntegros) e a interação destas com moléculas efetoras (substratos e agonistas naturais; fármacos inibidores, agonistas e antagonistas) ${ }^{9}$. Deste modo, pode-se planejar, numa base racional, novas drogas mais específicas e potentes, capazes de emprego terapêutico mais seguro.

Pelo exposto, conclui-se que a modelagem molecular, incluindo a análise conformacional e o cálculo de propriedades e parâmetros estereoeletrônicas e físico-químicos, auxilia a interpretação das correlações entre a estrutura química de uma substância e sua atividade farmacológica, sendo, portanto, uma importante ferramenta para o planejamento racional de novos fármacos ${ }^{2}$

\section{APLICAÇÕES DE MODELAGEM MOLECULAR EM QUÍMICA MEDICINAL}

Neste tópico descreve-se alguns resultados recentes do LASSBio ilustrativos dos projetos desenvolvidos em nosso grupo de pesquisas na aplicação de técnicas de modelagem molecular em Química Medicinal.

\section{Estudo de Inibidores de Cicloxigenase (COx) e 5-Lipoxigenase (5-LO): Proposta de Novos Inibidores Seletivos de 5-LO}

O ácido araquidônico (ácido 5-Z,8-Z,11-Z,14-Z-icosatetraenóico, AA), liberado a partir de fosfolipídeos de membranas celulares pela enzima fosfolipase $\mathrm{A}_{2}{ }^{35,36}$, desempenha um papel importante na inflamação. Como substrato para as enzimas 5-lipoxigenase (5-LO) e cicloxigenase (COx) - também conhecida como prostaglandina endoperóxido sintase (PGHS) - o ácido araquidônico produz, respectivamente, o hidroperóxido (AA-OOH) que é subsequentemente reduzido a leucotrienos (LTs), e o $\mathrm{PGH}_{2}$ que origina as prostaglandinas (PGs) (Fig. 1). Revisões recentemente publicadas descrevem vários aspectos dos inibidores de 5- $\mathrm{LO}^{37-39}$

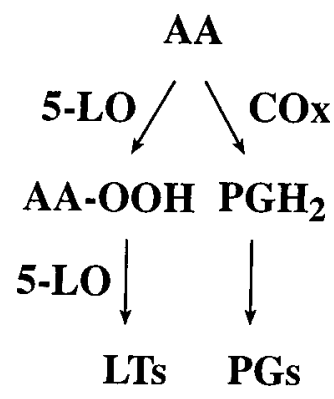

Figura 1. Esquema do metabolismo do ácido araquidônico (AA).
$\mathrm{O} \mathrm{LTB}_{4}$ é um potente agente quimiotáctil para as células inflamatórias (polimorfonucleares, PMN) e pode ter um papel importante na última fase da inflamação, comumente observada em pacientes asmáticos. Os $\mathrm{LTC}_{4}, \mathrm{LTD}_{4} \mathrm{e} \mathrm{LTE}_{4}$, coletivamente identificados como substâncias de reação lenta da anafilaxia (SRS-A), têm efeitos farmacológicos potentes sobre as contrações dos músculos lisos, o estimulo da secreção de muco bronquial e o aumento da permeabilidade vascular, sendo considerados mediadores importantes dos processos alérgicos ${ }^{40,41}$.

$\mathrm{O}$ emprego de técnicas de modelagem molecular permitiu que fossem calculadas superfícies de energia potencial (parciais) utilizando o Hamiltoniano $\mathrm{AM} 1^{42-45}$ para vários derivados de pirazolinas (1-2) e de indazolinonas (3-7), descritos como inibidores de COx e 5-LO. Foram também estudados alguns derivados de 5-tioaril-N-fenil-pirazóis (8a-g) sintetizados no LASSBio ${ }^{46}$ que, embora estruturalmente relacionados com compostos anti-edematogênicos da classe dos 5-arilamino-N-fenil-pirazóis, não apresentaram atividade antiinflamatória significativa.. Estes estudos visaram a identificação de propriedades estereoeletrônicas, dependentes das estruturas, que pudessem estar relacionadas à atividade inibitória. A partir dos resultados e considerando o mecanismo molecular de ação correntemente aceito para este tipo de atividade farmacológica, foi possível propor novos inibidores mais seletivos da enzima 5-LO ${ }^{42-45}$

A 5-LO é uma enzima ferro-não-heme dependente, encontrada primariamente em PMN e eosinófilos. Como dito acima, esta enzima catalisa a bioformação dos leucotrienos a partir do ácido araquidônico (Fig. 1), estando envolvida, portanto, nos eventos inflamatórios ${ }^{40,47}$. O mecanismo de ação de lipoxigenases proposto por Musser \& $\mathrm{Kreft}^{48}$, Chasteen et al. ${ }^{49} \mathrm{e}$ Schilstra et al. ${ }^{50}$ foi adotado em nossos estudos. Estes autores consideram a participação de um ciclo redox $\mathrm{Fe}(\mathrm{II}) / \mathrm{Fe}(\mathrm{III})$ neste mecanismo oxidativo.

Cucurou et $a l .{ }^{47}$ indicaram que no caso da inibição da lipoxigenase-1 de soja (L-1), os inibidores BW755c (1) e fenidona (2) são oxidados a um cátion-radical que seria a espécie ativa na inibição da atividade enzimática. A etapa determinante do processo parece ser a oxidação enzimática do átomo de nitrogênio heterocíclico (N1), destes inibidores (17), pelo $\mathrm{Fe}(\mathrm{III})^{48}$. A Figura 2 ilustra o mecanismo proposto. $\mathrm{O}$ processo de inativação de L-1 inicia-se com a oxidação da fenidona a um cátion-radical $\left(\mathrm{F}^{+\bullet}\right)^{51}$. Este cátion-radical $\left(\mathrm{F}^{+\bullet}\right)$ ou outras espécies radicalares $\left(\mathrm{F}^{*}\right)$ geradas pela atividade peroxidase de L-1 parecem estar envolvidos na inativação irreversível de lipoxigenases, entre elas a L-1 (Fig. 2).

Ensaios com agentes redutores tais como o ácido ascórbico e derivados de tióis (glutationa=GSH; etanotiol=RSH) foram rea$\operatorname{lizados}^{47}$, objetivando analisar o papel das espécies radicalares no processo de inativação de L-1. Os resultados demonstraram que ocorre redução dos derivados radicalares $\left(\mathrm{F}^{\bullet}\right.$ ou $\left.\mathrm{F}^{\boldsymbol{*}^{\bullet}}\right)$ à forma neutra (F) (Fig. 2). Entretanto, a ação nucleofílica do ácido ascórbico e dos tióis não foi observada com os metabólitos eletrofílicos da fenidona já que estudos com fenidona $\left[{ }^{14} \mathrm{C}\right]$ não revelaram a presença de adutos marcados ${ }^{47}$.

A oxidação posterior de $\mathrm{F}^{*}$ ou $\mathrm{F}^{{ }^{\bullet}}$ a 1 -fenil-1H-pirazol-3-ol poderia ocorrer através de diferentes reações (Fig. 2). Primeiramente, por dismutação, gerando fenidona e seu derivado desidrogenado (Fig. 2, via a) ${ }^{42}$. Em segundo lugar, a oxidação pela L-1 poderia levar a desidro-fenidona via carbocátion ou íon imônio, $\mathrm{F}^{+}$(Fig. 2, via b). Esta espécie poderia formar ligação covalente com a proteína por reação com um resíduo nucleofílico de um amino-ácido. Esta hipótese tem suporte experimental na correlação linear observada entre a formação de ligação covalente e a inativação da lipoxigenase ${ }^{47}$. O papel do oxigênio na inativação da L-1 sugere, finalmente, a possibilidade de oxidação do cátion-radical $\left(\mathrm{F}^{+*}\right)$ a desidro-fenidona e $\mathrm{O}_{2}{ }^{\circ-}$ (via c). Esta última espécie $\left(\mathrm{O}_{2}{ }^{\circ}\right)$ poderia ser responsável pela inativação da L-1 por um mecanismo relacionado à 


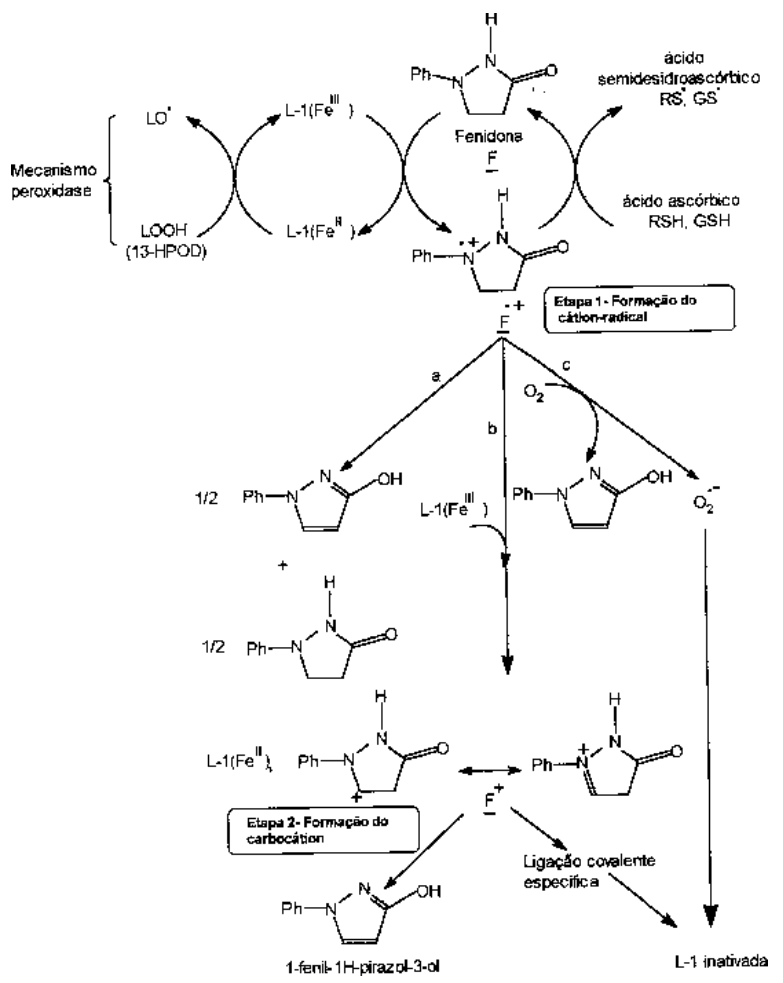

Figura 2. Possível mecanismo molecular da inativação da Lipoxigenase de soja (L-1) por 7 e 8 proposto por Cucurou et al. ${ }^{47}$

oxidação da metionina (Fig. 2).

$\mathrm{Na}$ Tabela I estão descritos os dados físico-químicos mais relevantes, calculados por AM1, assim como as atividades farmacológicas destes derivados. Os compostos 1-7 (Fig. 3,

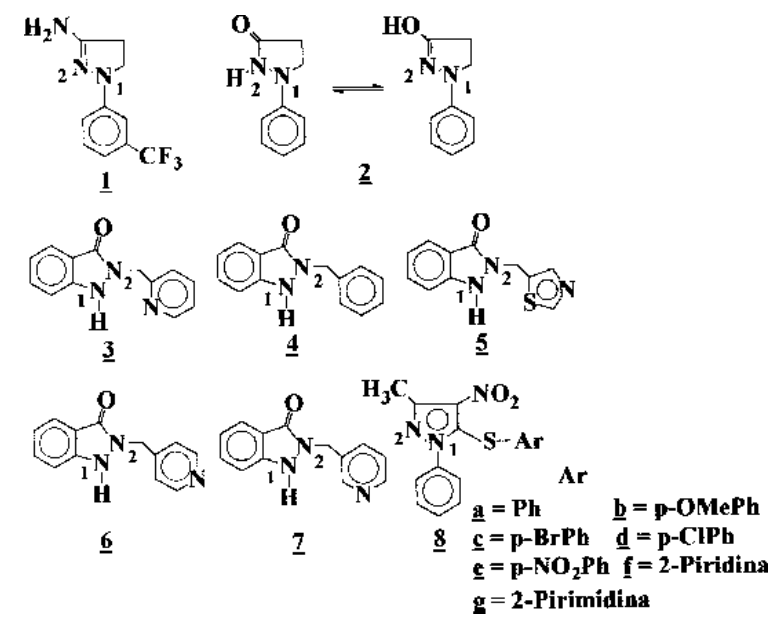

Figura 3. Inibidores de 5-LO e COx (1-7 e 8a-g).

Tabela I) são inibidores ${ }^{52}$ de COx e 5-LO, sendo o derivado ICI207968 (7) ${ }^{52}$ o mais seletivo a nível de 5-LO. Os compostos 8a-g (Fig. 3, Tabela I) foram sintetizados no LASSBio ${ }^{46}$ como prováveis bioisósteros com atividade antiinflamatória, apresentando, entretanto, fraca atividade. Os dados da Tabela I não evidenciaram qualquer relação entre os momentos de dipolo ou os potenciais de ionização e a atividade inibitória. Entretanto, as densidades eletrônicas (DE) sobre N1 são muito diferentes para os compostos ativos e inativos. Esta diferença sugere que altas densidades eletrônicas são desejáveis para a atividade.

As densidades eletrônicas de 8a-g parecem insuficientes para participarem do ciclo redox inibitório. Estes resultados suportam a hipótese mecanística mencionada anteriormente e justificam a fraca atividade observada para os derivados sintéticos da série $\mathbf{8}$. Os dados da Tabela I sugerem, também, que as DEs sobre N2 também são muito baixas para participarem do ciclo redox. A análise dos dados mostra que existe inversão de atividade atra-

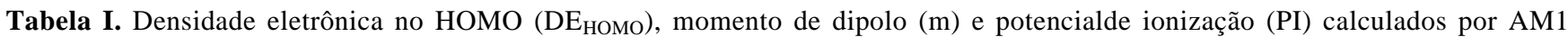
e atividade observada para os compostos 1-8:

\begin{tabular}{cccccccc}
\hline & \multicolumn{2}{c}{ DE Hомо } & $\mu$ & \multicolumn{3}{c}{ PI } & \multicolumn{3}{c}{$\mathrm{IC}_{50}(\mathrm{mM})\left(\right.$ in vitro ${ }^{\mathrm{c}}$} \\
& $\mathrm{N}(1)$ & $\mathrm{N}(2)$ & $(\mathrm{D})$ & $(\mathrm{eV})$ & $\mathrm{LO}$ & $\mathrm{COx}$ & LO/COx $^{2}$ \\
\hline 1 & 0,60 & 0,20 & 5,0 & 8,5 & 20,00 & 5 & $4: 1$ \\
$2^{\mathrm{a}}$ & 0,58 & 0,12 & 1,9 & 8,4 & 10,00 & 3 & $3: 1$ \\
$2^{\mathrm{b}}$ & 0,54 & 0,32 & 3,8 & 9,1 & 10,00 & 3 & $3: 1$ \\
3 & 0,51 & 0,27 & 4,0 & 8,8 & 0,27 & 13 & $1: 50$ \\
4 & 0,49 & 0,31 & 4,1 & 9,0 & 0,36 & 18 & $1: 50$ \\
5 & 0,49 & 0,29 & 3,1 & 9,1 & 1,80 & $>100$ & $1: 50$ \\
6 & 0,47 & 0,30 & 2,9 & 9,1 & 2,40 & 280 & $1: 100$ \\
7 & 0,45 & 0,34 & 2,7 & 9,2 & 1,50 & $>300$ & $1: 200$ \\
$8 \mathrm{a}^{\mathrm{d}}$ & 0,09 & 0,16 & 7,5 & 8,7 & - & - & - \\
$8 \mathrm{~b}$ & 0,08 & 0,16 & 4,5 & 8,8 & - & - & - \\
$8 \mathrm{c}$ & 0,05 & 0,07 & 5,5 & 9,0 & - & - & - \\
$8 \mathrm{~d}$ & 0,03 & 0,02 & 6,0 & 8,7 & - & - & - \\
$8 \mathrm{e}$ & 0,04 & 0,07 & 8,9 & 9,2 & - & - & - \\
$8 \mathrm{f}$ & 0,05 & 0,10 & 5,7 & 8,7 & - & - & - \\
$8 \mathrm{~g}$ & 0,06 & 0,12 & 5,0 & 8,9 & - & - & - \\
\hline
\end{tabular}

${ }^{\mathrm{a}}$ Forma enol ${ }^{\mathrm{b}}$ Forma cetona ${ }^{\mathrm{c}}$ Inibição de leucotrieno $\mathrm{B}_{4}$ (inibição de 5-LO) e prostaglandina $\mathrm{E}_{2}$ (inibição de COx) ${ }^{52}{ }^{\mathrm{d}} \mathrm{Resultados}$ farmacológicos não publicados 
vés da 5-LO e COx para os compostos $2\left(\mathrm{DE} \mathrm{N}_{1}=0,54\right)$ e 3 (DE $\left.\mathrm{N}_{1}=0,51\right)$, o que parece sugerir que valores menores de DE (37) estão associados com maior seletividade para 5-LO.

Como uma extensão desta hipótese, uma série de derivados triazólicos (9a-f) com as características estruturais mínimas necessárias à atividade desejada foram planejados, considerando o perfil farmacológico procurado ${ }^{42}$. Estes compostos, derivados do di-hidro-1,2,3-triazol (9a-f) (Fig. 4, Tabela II), são análogos estruturais do BW755c (1) ${ }^{47}$ e da fenidona (2) e pos-

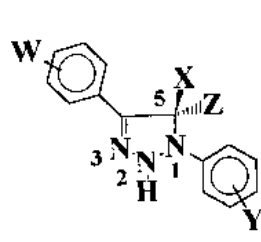

9

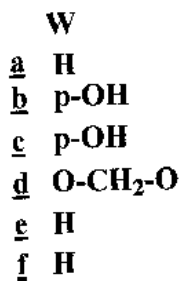

$\mathbf{X}$
$\mathbf{H}$
$\mathbf{H}$
$\mathbf{H}$
$\mathbf{H}$
$\mathbf{H}$
$\mathbf{M e}$

$\begin{array}{ll}\mathbf{Y} & \mathbf{Z} \\ \mathbf{H} & \mathbf{O H} \\ \mathbf{H} & \mathbf{O H} \\ \mathbf{m}-\mathrm{CF}_{\mathbf{3}} & \mathbf{O H} \\ \mathbf{H} & \mathbf{O H} \\ \mathbf{H} & \mathbf{H} \\ \mathbf{H} & \mathbf{O H}\end{array}$

Figura 4. Inibidores propostos 9a-f para a 5-LO (derivados 1,2,3triazólicos).

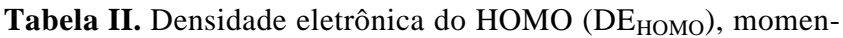
to de dipolo $(\mu)$ e potencial de ionização (PI) calculados por AM1 para os compostos 9a-f:

\begin{tabular}{cccccc}
\hline & \multicolumn{3}{c}{ DE $_{\text {номо }}$} & $\mu$ & PI \\
& $\mathrm{N}(1)$ & $\mathrm{N}(2)$ & $\mathrm{N}(3)$ & $(\mathrm{D})$ & $(\mathrm{eV})$ \\
\hline 9a & 0,41 & 0,26 & 0,06 & 2,8 & 8,9 \\
9b & 0,35 & 0,28 & 0,09 & 1,0 & 8,7 \\
9c & 0,06 & 0,26 & 0,20 & 1,1 & 8,9 \\
9d & 0,06 & 0,22 & 0,07 & 2,8 & 8,8 \\
9e & 0,43 & 0,27 & 0,13 & 3,3 & 8,8 \\
9f & 0,45 & 0,20 & 0,07 & 2,4 & 8,8 \\
\hline
\end{tabular}

suem um segundo anel fenila de forma a potencializar suas propriedades hidrofóbicas e, em consequência, aumentar a seletividade frente a $5-\mathrm{LO}^{53}$.

$\mathrm{O}$ padrão de substituição em $\mathrm{C} 5$ foi concebido de forma a permitir estudos mecanísticos. A Tabela II descreve os resultados obtidos para estes compostos pelo método AM1. Considerando a hipótese descrita acima, que correlaciona a atividade com a densidade eletrônica, espera-se que os derivados 9a, 9e e 9f se comportem como o composto 7, inibindo seletivamente a enzima 5-LO. Espera-se, por outro lado, que os compostos 9c e 9d sejam inativos.

Foi proposto, ainda, uma segunda série de derivados heterocíclicos baseada nos mesmos critérios farmacológicos, os derivados 10a-h (Fig. 5, Tabela III) ${ }^{45}$. A Tabela III contém resultados obtidos pelo método AM1. Como os compostos 8ag (Tabela I), as DEs sobre N1 destes derivados são muito baixas, impedindo a participação no ciclo redox $\mathrm{Fe}(\mathrm{II}) / \mathrm{Fe}(\mathrm{III})$. Entretanto, algumas densidades eletrônicas sobre N2 tem os valores desejados, o que permite antecipar que o composto $10 \mathbf{e}$ deve agir como um inibidor de ambas as enzimas 5-LO e COx, sendo seletivo frente a 5-LO. O composto 10a, no qual observou-se uma baixa densidade eletrônica sobre N2, deve ser ativo em relação a 5-LO mas inativo em relação a enzima COx.

Os resultados obtidos nestes estudos ${ }^{47}$ antecipam a hipótese de que a modulação da carga residual sobre o átomo de nitrogênio heteroaromático pode determinar as propriedades inibidoras sobre $\mathrm{COx} / 5-\mathrm{LO}$, permitindo o planejamento de inibidores seletivos de 5-LO. Outrossim, a conjugação de pro-

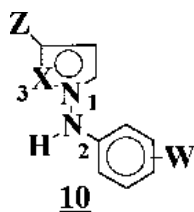

\begin{tabular}{|c|c|c|}
\hline $\mathbf{W}$ & & \\
\hline & $\mathbf{N}$ & \\
\hline $\begin{array}{ll}\underline{\mathbf{a}} & \mathbf{H} \\
\underline{\mathbf{b}} & \mathbf{H}\end{array}$ & $\mathbf{N}$ & $\begin{array}{l}\mathbf{H} \\
\mathrm{OH}\end{array}$ \\
\hline c $\mathrm{OCH}_{3}$ & $\mathbf{N}$ & H \\
\hline $\mathrm{H}_{3}$ & $\mathbf{N}$ & \\
\hline
\end{tabular}

$\begin{array}{llll} & \mathbf{W} & \mathbf{X} & \mathrm{Z} \\ \mathrm{e} & \mathrm{H} & \mathrm{CH} & \mathrm{H} \\ \underline{\mathrm{f}} & \mathrm{H} & \mathrm{CH} & \mathrm{OH} \\ \mathrm{g} & \mathrm{OCH} & \mathrm{CH} & \mathrm{H} \\ \underline{\mathrm{h}} & \mathrm{OCH} & \mathrm{CH} & \mathrm{OH}\end{array}$

Figura 5. Inibidores propostos 10a-h para a 5-LO (derivados pirrólicos e pirazólicos).

Tabela III. Densidade eletrônica do HOMO (DE $\left.\mathrm{HOMO}_{\mathrm{O}}\right)$, momento de dipolo $(\mu)$ e potencial de ionização (PI) calculados por AM1 para os compostos 10a-h:

\begin{tabular}{cccccc}
\hline & & $\begin{array}{c}\text { DE } \\
\text { HOMO }\end{array}$ & & $\mu$ & PI \\
& $\mathrm{N}(1)$ & $\mathrm{N}(2)$ & $\mathrm{X}(3)$ & $(\mathrm{D})$ & $(\mathrm{eV})$ \\
\hline $10 \mathrm{a}$ & 0,04 & 0,33 & 0,02 & 1,1 & 9,3 \\
$10 \mathrm{~b}$ & 0,24 & 0,19 & 0,07 & 2,2 & 9,3 \\
$10 \mathrm{c}$ & 0,03 & 0,19 & 0,02 & 1,6 & 8,9 \\
$10 \mathrm{~d}$ & 0,05 & 0,17 & 0,02 & 3,2 & 8,9 \\
$10 \mathrm{e}$ & 0,12 & 0,43 & - & 3,7 & 9,1 \\
$10 \mathrm{f}$ & 0,13 & 0,02 & - & 1,3 & 8,5 \\
$10 \mathrm{~g}$ & 0,03 & 0,02 & - & 1,7 & 8,7 \\
$10 \mathrm{~h}$ & 0,12 & 0,02 & - & 2,2 & 8,5 \\
\hline
\end{tabular}

priedades hidrofóbicas adequadas, determinará o perfil farmacocinético que as novas substâncias poderão apresentar, viabilizando sua avaliação farmacológica in vivo.

\section{Estudo Teórico da Tromboxana $A_{2}$ : Proposta de uma Conformação Bioativa}

Como mencionado anteriormente, a cicloxigenase (COx), também conhecida como prostaglandina endoperóxido sintase (PGHS), é responsável pela ciclização-oxidativa do ácido araquidônico (AA, 11) a endoperóxido de prostaglandina $\mathrm{H}_{2}$ $\left(\mathrm{PGH}_{2}, 12\right)$, que é isomerizado pela tromboxana sintase (TXS)

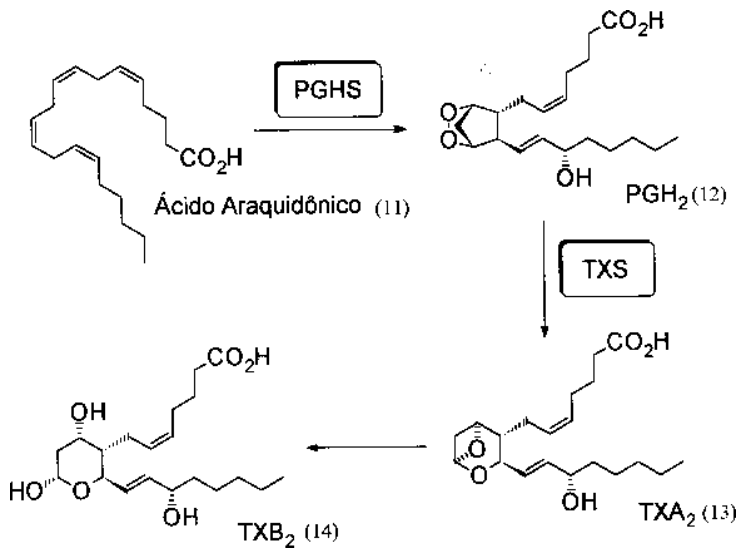

Figura 6. Bioformação da $T X A_{2}$ (13) e da $T X B_{2}$ (14)a partir do ácido araquidônico (11).

à tromboxana $\mathrm{A}_{2}\left(\mathrm{TXA}_{2}, \mathbf{1 3}\right)$, uma substância com meia vida de 3 minutos nas condições fisiológicas e que se transforma em tromboxana $\mathrm{B}_{2}\left(\mathrm{TXB}_{2}, \mathbf{1 4}\right)$, um metabólito estável com perfil biológico ${ }^{35}$ distinto (Fig. 6). 
A TXA $_{2}$ (13) é um vasoconstritor potente no sistema cardiovascular e um indutor potente da agregação plaquetária e da reação de liberação plaquetária no sistema sangüíneo, atuando a nível de receptores específicos. $\mathrm{O} \mathrm{PGH}_{2}$ (12) possui um perfil farmacológico semelhante ao da $\mathrm{TXA}_{2}$ (13) com propriedades agonísticas no receptor de $\mathrm{TXA}_{2}{ }^{35}$. Nestes sistemas biológicos a $\mathrm{TXB}_{2}(\mathbf{1 4})$ é inativa. $\mathrm{O}$ receptor de $\mathrm{TXA}_{2}$

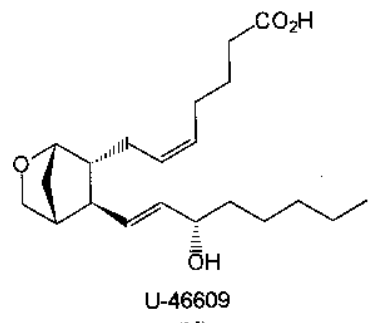

(15)

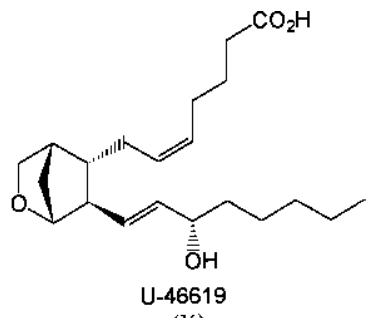

(16)
Figura 7. Estrutura dos prostanóides U-46609 (15) e U-46619 (16), análogos estáveis de $\mathrm{PGH}_{2}$ (12) e $\mathrm{TXA}_{2}$ (13).

(TP) é comumente referido como receptor de $\mathrm{TXA}_{2}$ e $\mathrm{PGH}_{2}$ uma vez que estes icosanóides produzem efeitos biológicos semelhantes. De fato, análogos estáveis do endoperóxido natural $\mathrm{PGH}_{2}$ (12) tais como U-44609 (15) e U-46619 (16) (Fig. 7) mimetizam os efeitos da $\mathrm{TXA}_{2}{ }^{54}(\mathbf{1 3})$.

Recentemente, a sequiência de aminoácidos do receptor TP humano foi deduzida a partir da sequiência de nucleotídeos do clone de cDNA que o codifica, utilizando-se tecido de placenta humana e de um clone parcial, obtido a partir de uma cultura de células leucêmicas megacariocíticas humanas ${ }^{55}$. Acredita-se que o receptor TP pertença à família de receptores acoplados à proteína-G (GPCR) por apresentar sete domínios transmembrânicos, uma característica dos GPCR, e uma significativa homologia sequencial com o receptor de rodopsina, um membro desta família ${ }^{55,56}$.

Estes conhecimentos permitiram que o receptor de $\mathrm{TXA}_{2}$ fosse modelado ${ }^{56}$ por mecânica molecular, com base em sua seqüência de aminoácidos e na estrutura tridimensional da bacteriorodopsina, obtida por criomicroscopia eletrônica. Esta enzima também contém sete segmentos transmembrânicos, mas como apresenta pouca homologia seqüencial com a rodopsina ${ }^{56}$, o modelo gerado deve ser usado com cautela, na falta da estrutura cristalográfica.

O sítio do receptor assim modelado apresenta dois resíduos de aminoácidos, Arg295 e Ser201, separados por uma região hidrofóbica. A Arg295 parece interagir com a carboxila terminal da $\operatorname{TXA}_{2}{ }^{55}(\mathbf{1 3})$ De fato, o ajuste da $\operatorname{TXA}_{2}(\mathbf{1 3})$ ao receptor modelado permite identificar as interações entre o grupamento ácido carboxílico terminal da TXA 2 (13) e o resíduo de Arg295, e entre a hidroxila alílica em C-15 e o resíduo de Ser201. Estes estudos, porém, não indicaram nenhuma interação envolvendo os átomos de oxigênio do sistema bis-oxabiciclo[3.1.1]-heptano e outros resíduos de aminoácido do receptor (Fig. 8).

A estrutura da $\operatorname{TXB}_{2}$ (14) (Fig. 6), o metabólito estável da $\mathrm{TXA}_{2}(\mathbf{1 3})$ que não possui propriedades agregantes plaquetárias, determinada por difração de raios- $\mathrm{X}^{57}$, mostrou duas formas de cristalização, denominadas $\alpha$ e $\beta$ (Fig. 9, a e b) de conformação semelhante, exceto quanto à orientação das cadeias $\alpha^{58}$, com a função ácido carboxílico terminal orientada em direções opostas. Neste estudo, foi sugerido que a estrutura da $\mathrm{TXB}_{2}$ (14) pode ser comparada com a da $\mathrm{TXA}_{2}$ (13) porque, apesar da $\mathrm{TXB}_{2}$ (14) ser inativa a nível das plaquetas, a preferência de ligação dos anéis endocíclicos são suficientemente diferentes para assegurar um reconhecimento molecular distinto entre estes dois prostanóides ${ }^{57}$.

$\mathrm{O}$ estudo de diversos agonistas e antagonistas do receptor

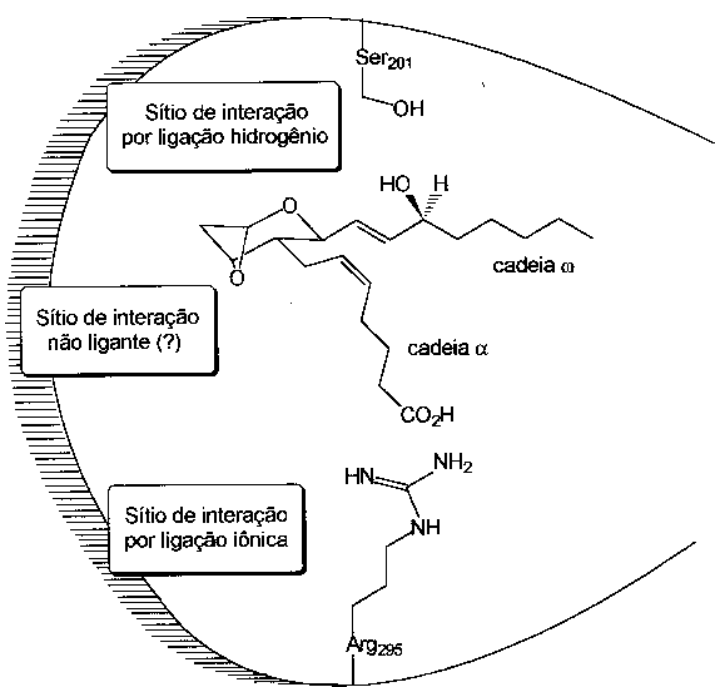

Figura 8. Representação esquemática do sítio receptor da tromboxana $A_{2}\left(T X A_{2}, 13\right)$, a partir do receptor TP modelado por Yamamoto et al. $^{56}$, demonstrando a interação entre o receptor TP e a TXA $(13)$.

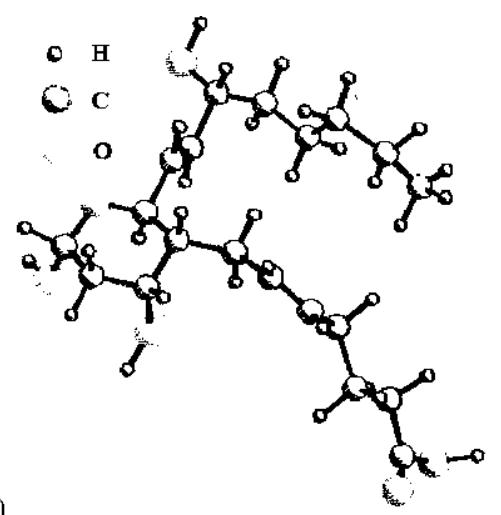

(a)

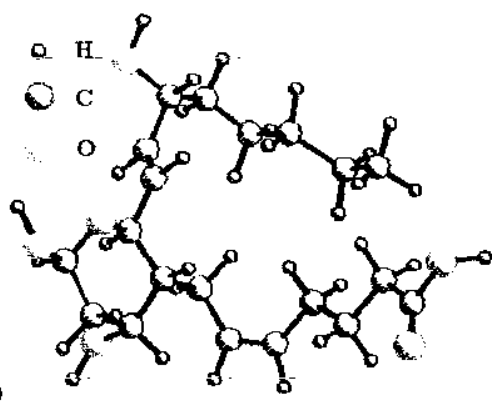

Figura 9. Estruturas cristalográficas $\alpha(a)$ e $\beta(b)$ da $T X B_{2}(14)^{57}$.

de $\mathrm{TXA}_{2}$ (13) por FTIR em solução diluída de $\mathrm{CCl}_{4}$, mostrou a formação de ligação hidrogênio intramolecular em muitos deles $^{59,60}$. Por exemplo, o composto U-46619 (16) (Fig. 7), um conhecido eficiente agonista do receptor TP, apresenta $80 \%$ das suas moléculas na conformação estabilizada por ligação hidrogênio intramolecular entre a carboxila e a hidroxila, formando um macrociclo de quinze membros, relativamente rígi$\mathrm{do}^{59}$. Nestes estudos, o $\mathrm{CCl}_{4}$ foi usado como solvente porque sua constante dielétrica $\left(\varepsilon=2,23\right.$ a $\left.25^{\circ} \mathrm{C}\right)$ é semelhante à encontrada no interior das proteínas. Os autores concluiram que embora a conformação predominante não deva ser a bioativa, porque compromete a função carboxila, considerada um farmacoforo importante para as atividades agonista e antagonista, esta não deve diferir muito daquela determinada em $\mathrm{CCl}_{4}{ }^{59,60}$. Este tipo de argumento não considera, entretanto, que 
o microambiente em que o agonista ou o antagonista interagem no receptor, isto é, o sítio receptor, é formado por resíduos de aminoácidos diversos, que podem inclusive atuar como doadores ou aceptores em ligações hidrogênio, alterando a conformação da molécula. Este microambiente, portanto, não é perfeitamente mimetizado por um solvente apolar incapaz de interagir com a molécula por ligações hidrogênio.

Pelo contrário, é razoável supor que compostos contendo, simultaneamente, grupos doadores e aceptores de hidrogênio, diluídos em solventes apolares, formem, preferencialmente, ligações hidrogênio intramoleculares, desde que a geometria molecular o permita, e o fator entrópico não seja desfavorável. De qualquer forma, como salientado no próprio trabalho ${ }^{59,60}$ o estudo conformacional da TXA $_{2}$ (13) em solução diluída de $\mathrm{CCl}_{4}$ pode ser útil como subsídio para a modelagem da conformação através de cálculos teóricos, usualmente realizados com a molécula isolada, simulando o vácuo $(\varepsilon=1)^{59,60}$.

Ezumi et al. ${ }^{61}$ também estudaram por mecânica molecular e orbitais moleculares (MNDO) a TXA $_{2}(\mathbf{1 3})$ e o composto U46619 (16) dentre outros compostos, e assumiram que a conformação bioativa não deve diferir muito das conformações mais estáveis no estado gasoso. Estes autores propuseram duas conformações bioativas para estes dois prostanóides, uma envolvendo ligação hidrogênio intramolecular, semelhante à encontrada em $\mathrm{CCl}_{4}$, e outra, mantendo basicamente a geometria anterior, porém, com a carboxila do ácido terminal e a hidroxila em C-15, opostamente orientadas ${ }^{61}$.

Recentemente, foi proposto por mecânica molecular e orbitais moleculares um modelo espacial do sítio farmacofórico do receptor de tromboxana $\mathrm{A}_{2}{ }^{62}$, com base no estudo das conformações mais estáveis de cinco conhecidos antagonistas de receptor de $\mathrm{TXA}_{2}$.

Nossos resultados sobre a análise conformacional da $\mathrm{TXA}_{2}$ (13) pelo método $\mathrm{AM} 1^{44,45,63,64}$, conseguiram classificar as conformações obtidas para a $\mathrm{TXA}_{2}(\mathbf{1 3})$ em dois grupos distintos. Um, representado pela conformação 1 (Fig. 10, a), onde ocorre formação de ligação hidrogênio intramolecular, como no caso do análogo U-46619 (16) ${ }^{59,61}$, e o outro, representado pela conformação 2 (Fig. 10, b), na qual as cadeias $\alpha$ e $\omega^{58}$

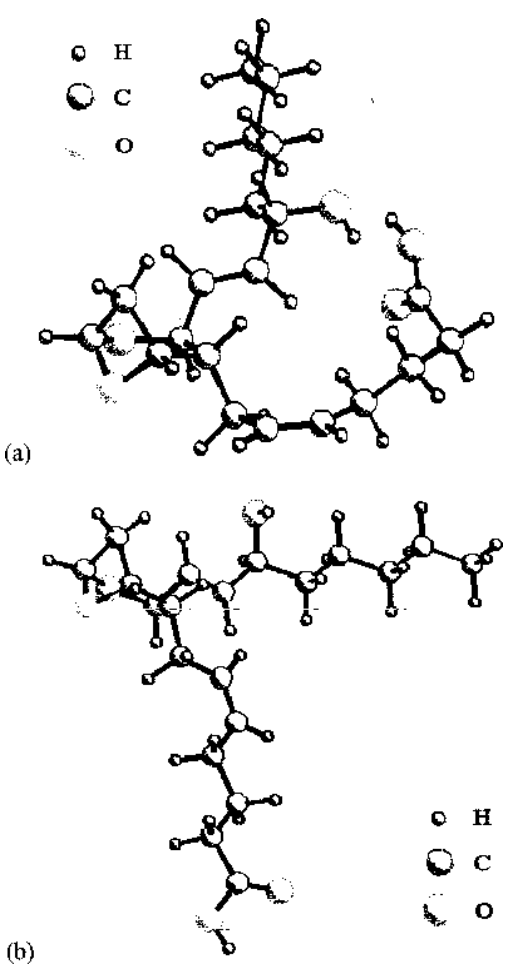

Figura 10. Conformações 1 (a) e 2 (b) da $T X A_{2}$ (13) obtidas por $A M 1^{45}$. estão relativamente afastadas e, tanto a carboxila do ácido terminal como a hidroxila em C-15 estão orientadas em direções opostas, porém distintas daquelas propostas por Ezumi et al.$^{61}$.

Estes resultados foram obtidos a partir de um estudo de sobreposição molecular, no qual foram considerados o átomo de carbono $\mathrm{C}-1$ da carboxila terminal, um dos átomos de oxigênio do anel endoperóxido ligado em C-9, e o átomo de oxigênio da hidroxila em C-15 da estrutura da $\mathrm{TXA}_{2}$ (13) (Fig. 6), para a sobreposição dos pares de conformações em análise.

As conformações 1 e 2 da TXA $_{2}$ (13), selecionadas por representarem conformações distintas, foram sobrepostas, então, às conformações $\alpha$ e $\beta$ da $\operatorname{TXB}_{2}$ (14) obtidas por difração de raios- $X^{57}$. As sobreposições da conformação $\alpha$ da $\mathrm{TXB}_{2}$ (14)

Tabela IV. Sobreposição das conformações $\alpha$ e $\beta$ da $\mathrm{TXB}_{2}$ (14) (por raios- $\mathrm{X}^{57}$ ) com as conformações 1 e 2 da TXA $_{2}(\mathbf{1 3})$ (por $\mathrm{AM} 1^{45}$ ), relacionando os desvios médios obtidos pelo pareamento de três átomos de cada estrutura:

\begin{tabular}{ccc}
\hline $\begin{array}{c}\text { Conformações sobrepostas } \\
\mathrm{TXB}_{2}\end{array}$ & $\begin{array}{r}\text { Desvio médio }(\AA) \text { da distância } \\
\text { entre } 3\end{array}$ & pares de átomos \\
\hline $\mathrm{a}$ & 1 & 3,3 \\
$\mathrm{a}$ & 2 & 0,8 \\
$\mathrm{~b}$ & 1 & 2,7 \\
$\mathrm{~b}$ & 2 & 0,6 \\
\hline
\end{tabular}

com as conformações 1 e 2 da TXA $_{2}$ (13) apresentaram desvios médios de 3,3 e $0,8 \AA$, respectivamente, enquanto que as sobreposições da conformação $\beta$ da $\mathrm{TXB}_{2}$ (14) com as conformações 1 e 2 da TXA $_{2}$ (13) apresentaram, desvios médios de 2,7 e $0,6 \AA$, respectivamente (Tabela IV).

Assim, as sobreposições obtidas com os melhores níveis de similaridade conformacional, ocorreram entre as conformações $\alpha$ ou $\beta$ da $\operatorname{TXB}_{2}(\mathbf{1 4})$ e a conformação 2 da $\operatorname{TXA}_{2}(\mathbf{1 3})$. Cabe ressaltar que a $\mathrm{TXB}_{2}(\mathbf{1 4})$ não apresenta atividade a nível de receptor de $\mathrm{TXA}_{2}(\mathbf{1 3})$ e, portanto, a melhor sobreposição poderia ser desfavorável para a conformação 2 da $\mathrm{TXA}_{2}(\mathbf{1 3})$. Entretanto, observando-se melhor a estrutura da $\mathrm{TXB}_{2}$, podese notar que o sistema oxacíclico apresenta duas hidroxilas, conferindo elevada hidrofilia a esta região da molécula, distintamente ao que ocorre na $\mathrm{TXA}_{2}(\mathbf{1 3})$. Como conseqüência, este autacóide não deve ser reconhecido pelo receptor $\mathrm{TP}$, muito provavelmente, devido a esta diferença de caráter lipofílico ao nível da sub-unidade estrutural complementar ao sítio hidrofóbico estereo-exigente do receptor $\mathrm{TP}^{62}$ e não porque apresentaria uma conformação inadequada.

Os resultados destes estudos indicam que a conformação 2 pode representar a conformação bioativa da $\operatorname{TXA}_{2}(\mathbf{1 3})$, possuindo como referência, uma conformação similar da $\operatorname{TXB}_{2}(\mathbf{1 4})$, no estado sólido, podendo ser então utilizada como modelo farmacofórico no planejamento de novos antagonistas de rceptor $\mathrm{TP}^{45,63}$

\section{Estudos de Nova Classe de Antagonistas do PAF Baseados no Sistema Protótipo Biciclo[3.3.0]-2-oxaoctano, como Isóstero Cíclico}

O fator de ativação plaquetária (PAF, 17) é um mediador celular que foi inicialmente identificado como um estimulante da agregação plaquetária ${ }^{65}$ e como agente hipotensivo ${ }^{66}$. Posteriormente, foi reconhecido como ativador dos leucócitos polimorfonucleares, monócitos e macrófagos ${ }^{67}$ e como estimulante do aumento da permeabilidade vascular ${ }^{68}$, da broncoconstrição e do choque circulatório ${ }^{69}$. Estes efeitos fisiológicos estão relacionados a uma série de estados patológicos, tais como 
a asma, isquemias cerebral, renal e do miocárdio, ulceração gástrica, psoríase e choque endotóxico ${ }^{69}$.

O composto 17 é um fosfolipídeo de estrutura geral 1-Oalquil-2-acetil-sn-gliceril-3-fosfocolina ${ }^{70}$ (Fig. 11), possuindo<smiles>C[14CH2]OC[C@H](COP(=O)([O-])OCC[N+](C)(C)C)OC(C)O</smiles>

Figura 11. Estrutura do PAF (17), $n=15$ oи 17.

predominantemente, nos neutrófilos humanos, grupamentos O-alquila lineares com 16 e 18 átomos de carbono ${ }^{71}$. O $(R)$ enantiômero é consideravelmente mais ativo do que o $(S)^{71}$. Sua bioformação ocorre na membrana celular em consequência de diversos estímulos físicos e químicos externos.

Receptores específicos presentes na membrana citoplasmática de células-alvo, incluindo plaquetas, macrófagos, neutrófilos, leucócitos, eosinófilos, entre outros, atuam como mediadores das ações de $\mathbf{1 7}^{\mathbf{7 2}}$. Após a clonagem e a determinação de sua sequência primária, o receptor do PAF (PAFr) foi identificado como membro da família dos receptores celulares acoplados a proteínas $G^{73}$. Todavia, sua estrutura tridimensional permanece desconhecida.

Tentativas foram feitas para modelar o $\mathrm{PAFr}^{74,75}$, mas os modelos resultantes ainda são muito imprecisos para explicar as sutis exigências estruturais que resultam em elevada afinidade de seus agonistas e antagonistas ${ }^{76}$. Um modelo mais específico de receptor ${ }^{76}$ foi desenvolvido usando a técnica de Monte Carlo "Salto de Boltzmann" para explicar o binding da classe de antagonistas heterocíclicos de nitrogênio-sp².

Mais recentemente foi proposto, por Bures et al. ${ }^{77}$, um mapa

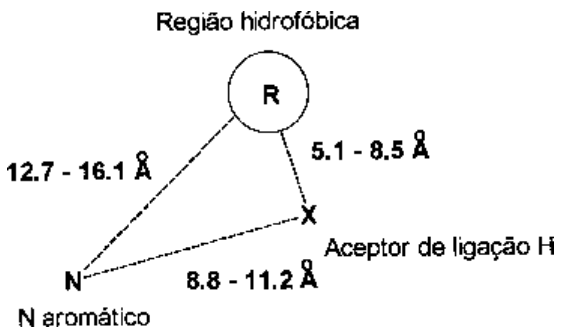

Figura 12. Mapa farmacofórico para antagonistas do $P A F^{77}$.

farmacofórico (Fig. 12) para antagonistas do PAF (PAFant), desenvolvido a partir da estrutura tridimensional de cinco antagonistas potentes conhecidos de $\mathbf{1 7}$, de acordo com o concei-

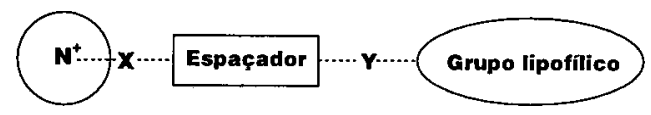

Figura 13. Representação esquemática dos antagonistas do PAF denitrogênio quaternário: $X$ representa um isóstero de fosfato $e$ $Y$ representa um isóstero de éster $6^{9}$.

to de Farmer de um ligante com três sítios para uma alta afinidade antagonista-receptor ${ }^{62}$.

A primeira classe desenvolvida de PAFant foi a dos antagonistas com nitrogênio quaternário, estruturalmente relacionados a $1 \mathbf{7}^{69}$, representados esquematicamente na Fig. 13.

No âmbito dos interesses de pesquisas do LASSBio, particularmente a descoberta de novos compostos protótipos úteis no
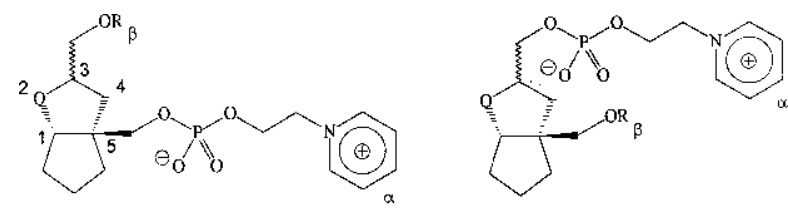

$$
3 \beta, 5 \alpha\left\{\begin{array}{l}
3(S) \beta, 5 \alpha \text { (endo): } 18 \mathrm{a} \\
3(\mathrm{R}) \beta, 5 \alpha \text { (exo): } 18 \mathrm{c}
\end{array} \quad 3 \alpha, 5 \beta\left\{\begin{array}{l}
3(S) \alpha, 5 \beta \text { (endo): } 18 \mathrm{~b} \\
3(\mathrm{R}) \alpha, 5 \beta \text { (exo): } 18 \mathrm{~d}
\end{array}\right.\right.
$$

Figura 14. Estruturas diastereoisoméricas dos antagonistas (18a-d) de 17 propostos como análogos conformacionalmente restritos, baseados no biciclo[3.3.0]-2-oxaoctano.

tratamento de patologias trombóticas, decidimos desenvolver uma nova classe de derivados PAFant possuindo o sistema biciclo[3.3.0]-2-oxaoctano (18a-d) como análogos estruturais de 17 conformacionalmente restritos (Fig. 14) ${ }^{78-81}$. Estas estruturas foram propostas supondo-se que a interação antagonista-PAFr é principalmente de natureza entrópica, como tem sido sugerido para outros sistemas ${ }^{82,83}$. A redução da flexibilidade molecular apresentada pelo sistema bicíclico em relação ao esqueleto de glicerol de 17 resultaria em uma menor penalidade entrópica paga pelo antagonista ao se ligar ao receptor, compensando, pelo menos em parte, uma variação menos favorável na entalpia do processo ${ }^{84}$.

Os estudos de modelagem molecular destas substâncias visaram definir, dentre os diastereoisomêros passíveis de síntese a partir do biciclo[3.3.0]-2-oxaoctano (i.e. 18a-d), o isômero com maior similaridade estrutural com o agonista. Os cálculos foram executados com o Hamiltoniano AM1 do programa de orbitais moleculares semi-empíricos MOPAC $6.0^{85} \mathrm{em}$ uma estação de trabalho IBM RISC System/6000 ${ }^{78-79}$. Como as estruturas descritas são compostas das mesmas unidades básicas, empregamos como estratégia para economizar tempo de máquina a subdivisão das estruturas previamente otimizadas em 3

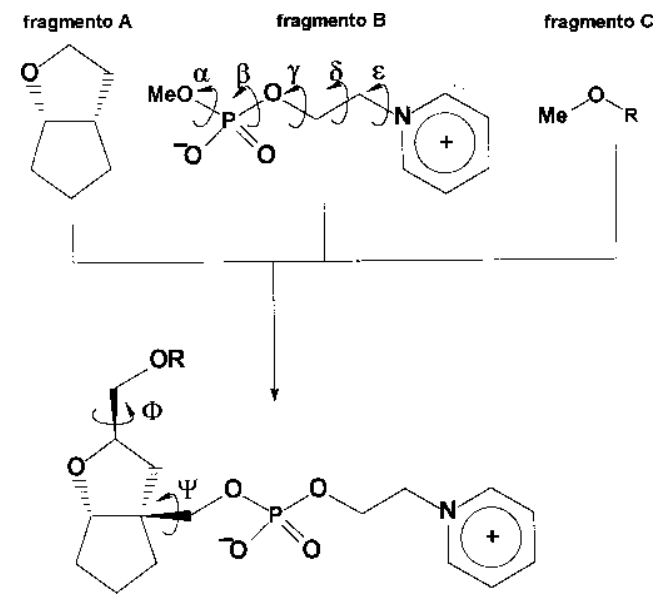

Figura 15. Representação esquemática do procedimento de modelagem molecular usado para definir as estruturas de energia mínima. Os ângulos diedros em destaque foram avaliados conforme descrito no texto. A estrutura recomposta representada corresponde ao diastereoisomêro $\mathbf{1 8 c}$.

fragmentos (Fig. 15). Cada ângulo de torção do fragmento B foi varrido isoladamente entre $0^{\circ}$ e $360^{\circ}$ por incrementos de $20^{\circ}$. As estruturas de energia mínima encontradas nestas superfícies parciais de energia potencial (SEP) foram totalmente caracterizadas por suas matrizes de Hess.

Os fragmentos de menor energia assim identificados foram recompostos nas estruturas originais (18a-d) e os ângulos ao 
redor das ligações de junção foram avaliados independentemente entre $0^{\circ}$ e $360^{\circ}$ por incrementos de $30^{\circ}$. Uma completa relaxação da geometria foi permitida nesta etapa e não foi observada nenhuma alteração significativa nos valores iniciais dos ângulos de torção previamente pesquisados. As estruturas de menor energia assim obtidas foram completamente reotimizadas (método $\mathrm{BFGS}^{86-89}$ ) adotando-se uma norma de gradiente menor do que $0.1 \mathrm{kcal} /(\AA$ ou $\mathrm{rad})$. Estas estruturas foram inequivocamente caracterizadas como mínimos de energia pela análise de suas respectivas matrizes de Hess.

Inicialmente, examinamos os derivados metílicos dos antagonistas propostos (18a-d, $\left.\mathrm{R}=\mathrm{CH}_{3}\right)$. Para se avaliar as estruturas obtidas, utilizamos o mapa farmacofórico desenvolvido por Bures et al. ${ }^{77}$ para antagonistas de 17 (Fig. 12). Para comparação das estruturas 18 com o mapa da Fig. 12, escolhemos o grupamento metila como o equivalente da "região hidrofóbica" do sítio receptor; o átomo de oxigênio do sistema bicíclico como o aceptor de ligação hidrogênio, e o átomo de nitrogênio piridínico como o $\mathrm{N}$-aromático. Apesar dos átomos de nitrogênio das estruturas dos antagonistas envolvidos na geração do mapa farmacofórico não possuirem carga positiva permanente,

Tabela V. Dados de distância e calor de formação $\left(\mathrm{DH}_{\mathrm{f}}\right)$ para os derivados metílicos dos antagonistas propostos (18a-d, $\mathrm{R}=\mathrm{Me}$ ). Para definição do código dos antagonistas, veja a Fig. 14. N-R representa a distância $\mathrm{N}$ aromático-região hidrofóbica, $\mathrm{X}-\mathrm{R}$, a distância aceptor de ligação H-região hidrofóbica e N$\mathrm{X}$, a distância $\mathrm{N}$ aromático-aceptor de ligação $\mathrm{H}$. Os números em negrito estão de acordo com o modelo ${ }^{77}$.

\begin{tabular}{ccccc}
\hline Estrutura & $18 \mathrm{a}$ & $18 \mathrm{~b}$ & $18 \mathrm{c}$ & $18 \mathrm{~d}$ \\
\hline $\mathrm{N}-\mathrm{R}(\AA)$ & 11,8 & 9,3 & 7,2 & 7,5 \\
$\mathrm{X}-\mathrm{R}(\AA)$ & 3,1 & $\mathbf{5 , 7}$ & 4,4 & $\mathbf{5 , 3}$ \\
$\mathrm{N}-\mathrm{X}(\AA)$ & $\mathbf{9 , 3}$ & 8,1 & $\mathbf{8 , 9}$ & 8,4 \\
$\Delta \mathrm{H}_{\mathrm{f}}(\mathrm{kcal} / \mathrm{mol})$ & $-289,5$ & $-287,5$ & $-290,54$ & $-289,84$ \\
\hline
\end{tabular}

como nos antagonistas que propusemos, Bures et al. sugerem que estes átomos podem estar na forma protonada ao interagir com o receptor ${ }^{77}$. Os resultados obtidos para $\left(\mathbf{1 8 a}-\mathbf{d}, \mathrm{R}=\mathrm{CH}_{3}\right)$ encontram-se resumidos na Tabela $\mathrm{V}$, juntamente com os calores de formação calculados $\left(\Delta \mathrm{H}_{\mathrm{f}}\right)$.

$\mathrm{A}$ análise da Tabela $\mathrm{V}$ indica que as quatro estruturas têm energias semelhantes, o que sugere que estas são principalmente dependentes de interações de curta distância. Pode-se observar que nenhum dos derivados metilados dos antagonistas propostos 18a-d encaixa-se completamente no mapa farmacofórico. No caso dos derivados $\mathbf{1 8 b}$ e $\mathbf{1 8 d}$, a substituição da cadeia a na posição 3 do sistema bicíclico coloca o átomo de nitrogênio aromático muito próximo do aceptor de ligação hidrogênio. Por outro lado, as dificuldades do ajuste das estruturas 18a e 18c ao mapa localizam-se em ambas as distâncias que envolvem a "região hidrofóbica". Como estas distâncias podem, em princípio, ser otimizadas pelo aumento da cadeia alquílica, decidimos avaliar o efeito da presença de cadeias mais longas nas estruturas 18a e 18c, buscando maximizar seus padrões de ajuste ao modelo farmacofórico.

As conformações mais estendidas de quatro diferentes cadeias alquílicas (alila, propila, butila e hexila) foram substituídas no fragmento C. Após otimização, estes novos fragmentos foram ancorados aos fragmentos A e B e o ângulo de torção das ligações de junção avaliado como antes. As estruturas de menor energia tiveram suas geometrias otimizadas e caracterizadas de acordo com os critérios adotados anteriormente. Os resultados encontram-se na Tabela VI. As distâncias entre o nitrogênio aromático e o aceptor de ligação de hidrogênio, naturalmente, permanecem de acordo com o modelo. Duas referências diferentes podem agora ser adotadas para se avaliar as distâncias que envolvem a cadeia alquílica: o seu limite superior (adotando o átomo de carbono mais distante) ou o seu "centro de massa" (adotando a distância média entre os átomos de carbono mais próximo e mais distante). Adotando-se como referência o "centro de massa" da cadeia alquílica, o derivado hexílico (18a, R=hex) se encaixa ao modelo. Nos derivados 18c, a configuração relativa cis das cadeias $\alpha$ e $\beta$ coloca o nitrogênio aromático e a região hidrofóbica próximos demais, prejudicando seu ajuste ao modelo farmacofórico.

Quando consideramos para comparação o limite superior da cadeia alquílica, os derivados $\mathbf{1 8 c}$ também não se ajustam ao mapa farmacofórico, mas, agora, praticamente todos os derivados 18a se ajustam. A distância entre o aceptor de ligação hidrogênio e a região hidrofóbica do derivado alílico de 18a está ligeiramente abaixo do valor mínimo $(5,1 \AA)$ correspondente no mapa; no derivado hexílico, esta distância é maior $(10,69 \AA)$ do que o valor máximo correspondente do mapa $(8,5$ $\AA$ ), mas esta distância reflete apenas os limite superior das estruturas modeladas. O PAFr deve provavelmente aceitar cadeias alquílicas maiores, já que a "região hidrofóbica" presente em 17 é bastante longa.

Estes resultados subsidiaram a síntese de derivados estruturalmente relacionados com $\mathbf{1 8 a}$, ora em andamento no LASSBio $^{90}$.

\section{CONCLUSÕES}

O uso integrado de conhecimentos teóricos e experimentais, multidisciplinares, no estudo de problemas de interesse bioló-

Tabela VI. Dados de distância e calor de formação $\left(\mathrm{DH}_{\mathrm{f}}\right)$ para os derivados de cadeia longa dos antagonistas propostos (18a) e (18c). Para definição do código dos antagonistas, veja a Fig. 14. N-R representa a distância N aromático-região hidrofóbica, X-R, a distância aceptor de ligação H-região hidrofóbica e N-X, a distância N aromático-aceptor de ligação H. CM representa centro de massa e LS, o limite superior. Os números em negrito estão de acordo com o modelo 77 .

\begin{tabular}{ccccccccc}
\hline R & \multicolumn{2}{c}{ alila } & \multicolumn{2}{c}{ propila } & \multicolumn{2}{c}{ butila } & \multicolumn{2}{c}{ hexila } \\
\hline distância & $18 \mathrm{a}$ & $18 \mathrm{c}$ & $18 \mathrm{a}$ & $18 \mathrm{c}$ & $18 \mathrm{a}$ & $18 \mathrm{c}$ & $18 \mathrm{a}$ & $18 \mathrm{c}$ \\
N-R (CM) & $\mathbf{1 2 , 8 9}$ & 7,45 & $\mathbf{1 2 , 9 2}$ & 7,52 & $\mathbf{1 3 , 5 0}$ & 7,74 & $\mathbf{1 4 , 6 4}$ & 8,51 \\
N-R (LS) & $\mathbf{1 3 , 9 4}$ & 7,77 & $\mathbf{1 3 , 9 9}$ & 7,86 & $\mathbf{1 5 , 1 7}$ & 8,33 & 17,44 & 9,81 \\
X-R (CM) & 3,97 & $\mathbf{5 , 6 7}$ & 4,09 & $\mathbf{5 , 6 8}$ & 4,78 & $\mathbf{6 , 3 4}$ & $\mathbf{5 , 9 5}$ & $\mathbf{7 , 5 7}$ \\
X-R (LS) & 4,96 & $\mathbf{6 , 8 9}$ & 5,10 & $\mathbf{6 , 9 0}$ & $\mathbf{6 , 5 0}$ & $\mathbf{8 , 2 4}$ & 8,83 & 10,69 \\
N-X & $\mathbf{9 , 3 4}$ & $\mathbf{8 , 8 6}$ & $\mathbf{9 , 2 5}$ & $\mathbf{8 , 8 7}$ & $\mathbf{9 , 2 4}$ & $\mathbf{8 , 8 8}$ & $\mathbf{9 , 2 5}$ & $\mathbf{8 , 8 8}$ \\
$\Delta$ H $_{\mathrm{f}}(\mathrm{kcal} / \mathrm{mol})$ & $-269,3$ & $-271,4$ & $-301,9$ & $-302,9$ & $-308,7$ & $-309,7$ & $-322,4$ & $-323,4$ \\
\hline
\end{tabular}


gico incluiu, recentemente, a modelagem molecular assistida por computadores (CAMM "computer-assisted molecular modeling” ou CADD "computer-aided drug design", Fig. 16). Metodologias tais como 3D-QSAR ${ }^{11}$, técnicas de química combinatória $^{92,93}$, esta representando fontes de novo de estruturas-protótipo de um ligante enzimático seletivo e antagonistas/ agonistas de bioreceptores, dentre outras técnicas computacionais, representam estratégias modernas, essenciais ao planejamento racional de fármacos baseados na estrutura ${ }^{94}$. Estas no-

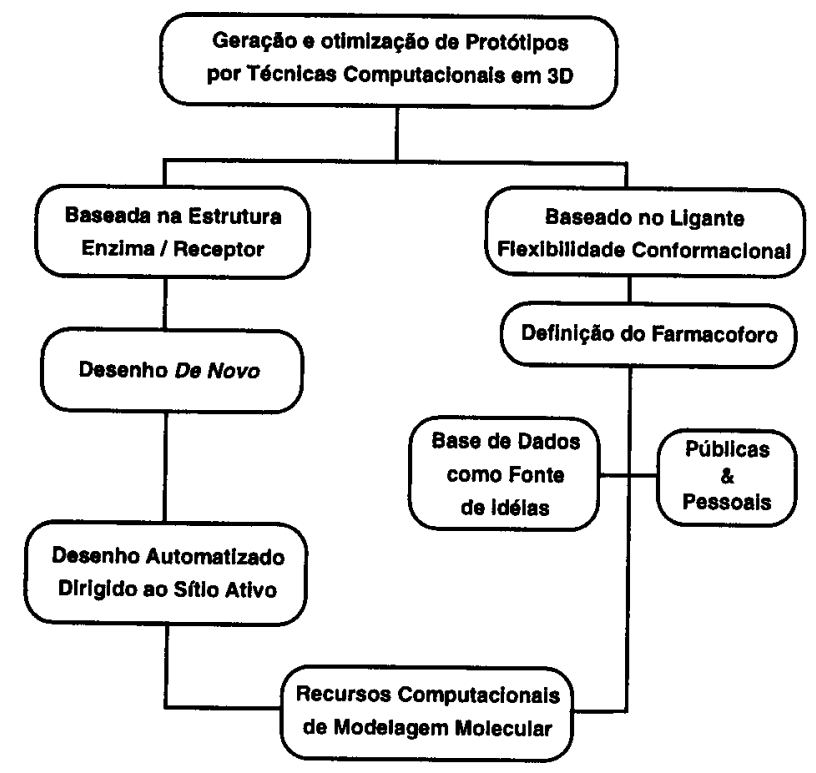

Figura 16. Geração de compostos-protótipos por técnicas de modelagem molecular.

vas metodologias são capazes de viabilizar a descoberta racional de drogas, baseada no paradigma de similaridade e complementaridade molecular, hoje empregado universalmente em laboratórios de pesquisa das indústrias farmacêuticas para acesso a novos fármacos eficientes, seletivos e de uso mais seguro.

\section{AGRADECIMENTOS}

Os autores agradecem as bolsas de pós-graduação de CRR (e-mail: rangel@aix143.iq.ufrj.br), MGA (e-mail: magaly@ aix143.iq.ufrj.br) e CMRS (e-mail: mauricio@aix143.iq.ufrj.br) e de pesquisa de EJB (e-mail: eliezer.b@unikey.com.br)e RBA (e-mail: bicca@iq.ufrj.br) das agências financiadoras CNPq e CAPES. As correspondências podem ser enviadas para Eliezer J. Barreiro, Laboratório de Avaliação e Síntese de Substâncias Bioativas (LASSBio), Faculdade de Farmácia, UFRJ. CP: 68006, CEP: 21944-390, Rio de Janeiro, RJ, Brasil. Fax (021) 260-2299, (021) 280-1784, ramal: 220.

\section{REFERÊNCIAS}

1. Este trabalho é a contribuição número 14 do LASSBio, UFRJ.

2. Cohen, N. C., Blaney, J. M., Humblet, C., Gund, P. \& Barry, D. C. J. Med. Chem. 1990, 33, 883.

3. Silverman, R. B. The organic chemistry of drug design and drug action. Academic Press, San Diego, 1992.

4. Eliel, E. L., Wien, S. H. \& Mander, L. N. Stereochemistry of organic compounds. Wiley-Interscience, New York, 1994.

5. Cohen, N. D., Blaney, J. M., Howard, A. E. \& Kollman, P. A. J. Med. Chem. 1988, 31, 1669.

6. Abraham, D. J. X-ray crystallografy and drug design. In: Perun, T. J. \& Propst, C. L. (eds) Computer-aided drug design: methods and applications. Marcel Dekker, New York, 1989.

7. Boyd, D. B. Compendium of software for molecular modeling. In: Lipkowitz, K. B. \& Boyd, D. B. (eds) Reviews in computational chemistry. $\mathrm{VCH} \mathrm{Pub}$, New York, 1990.

8. Martin, Y. C., Bures, M. G. \& Willett, P. Searching Databases of Three-Dimensional Structures. In: Lipkowitz, K. B. \& Boyd, D. B. (eds) Reviews in computational chemistry. VCH Pub, New York, 1990.

9. Propst, C. L. \& Perun, T. J. Introduction to computeraided drug design. In: Perun, T. J. \& Propst, C. L. (eds) Computer-aided drug design: methods and applications. Marcel Dekker, New York, 1989.

10. Lipkowitz, K. B. \& Boyd, D. B. (eds) Reviews in computational chemistry. VCH Pub, New York, 1990.

11. Fesik, S. W. Approaches to drug design using nuclear magnetic resonance spectroscopy. In: Perun, T. J. \& Propst, C. L. (eds) Computer-aided drug design: methods and applications. Marcel Dekker, New York, 1989.

12. Charretier, E. \& Guéron, M. Biochem. Cell. Biol. 1991, 69, 322.

13. Burkert, U. \& Allinger, N. L. Molecular mechanics. ACS Monograph 177. American Chemical Society, Washington, DC, 1982.

14. Clark, T. A handbook of computational chemistry: a pratical guide to chemical structure and energy calculations. John Wiley \& Sons, Friedrich, 1985.

15. Brewster, M. E., Pop, E., Huang, M. J. \& Bodor, N. Heterocycles 1994, 37, 1373.

16. Boyd, B. D. \& Lipkowitz, K. B. J. Chem. Ed. 1982, 269.

17. Hirst, D. A. A Computacional Approach to Chemistry. Blackwell Scientific Publications, Oxford, 1990.

18. Szabo, A. \& Ostlind, N. S. Modern Quantum Chemistry. McGraw-Hill, New York, 1989.

19. Dewar, M. J. S., Zoebisch, E. G., Healy, E. F. \& Stewart, J. J. P. J. Am. Chem. Soc. 1985, 107, 3902.

20. Stewart, J. J. P. J. Comput. Chem. 1989, 10, 209.

21. Stewart, J. J. P. J. Comput. Chem. 1989, 10, 221.

22. Zheng, Y. J., Merz, K. M. J. Comp. Chem. 1992, 13, 1151 .

23. Jurema, M. W. \& Shields, G. C. J. Comp. Chem. 1993, 14,89 .

24. Jurema, M. W., Kirschner, K. N. \& Shields, G. C. J. Comp. Chem. 1993, 14, 1326.

25. Almeida, W. B. \& O'Malley, P. J. J. Mol. Struct. (Theochem) 1992, 253, 349.

26. Bofill, J. M. \& Comajuan, M. J. Comp.Chem. 1995, 16, 1326.

27. Sant'Anna, C. M. R., Alencastro, R. B., Barreiro, E. J. \& Fraga, C. A. M. J. Mol. Struct. (Theochem) 1995, 340, 193.

28. Milne, G. W. Nicklaus, M. C., Hoposek, K. M., J. Mol. Struct. 1993, 291, 89.

29. Martin, Y. C. J. Med. Chem. 1992, 35, 2145.

30. Humblet, C. \& Dunbar Jr., J. B. Ann. Rep. Med. Chem. 1993, 28, 275.

31. Korolkovas, A. \& Burckhalter, J. H. Essential of medicinal chemistry. New York, Wiley-Interscience, 1976.

32. Fleming, I. Frontier orbitals and organic chemical reactions. Wiley \& Sons, London, 1978.

33. Gund, P., Barry, D. C., Blaney, J. M. \& Cohen, C. J. Med. Chem. 1988, 31, 2230.

34. Motta Neto, J. D., Zerner, M. C. \& Alencastro, R. B. Intern. J. Quantum Chem.: Quantum Biol. Symp. 1992, $19,225$.

35. Campbell, W. B. Lipid-derived autacoids: eicosanoids and platelet-activating factor. In: Gilman, A. G., Rall, T. W., 
Nies, A. S. \& Taylor, P. (eds) Goodman \& Gilman's the pharmacological basis of therapeutics. $8^{\text {th }}$ ed. Pergamon Press, New York, 1990.

36. Decker, K. Basic mechanisms of the inflammatory response. In: Sies, H., Flohé, L. \& Zimmer, G. (eds) Molecular aspects of inflammation. Springer-Verlag, Berlin, 1991.

37. Ford-Hutchison, A. W., Gressner, M. \& Young, R. N. Ann. Rev. Biochem. 1994, 63, 383.

38. Friedman, B. \& Margolskee, D. J. Lipid Mediators Allerg. Dis. Respir. Tract 1994, 207.

39. Robinson, C. Lipid Mediators Allerg. Dis. Respir. Tract 1994, 1.

40. Shaw, A. \& Krell, R. D. J. Med. Chem. 1991, 34, 1236.

41. Kreutner, W. \& Siegel, H. Ann. Rep. Med. Chem. 1984, 19, 241.

42. Rodrigues. C. R. Tese de mestrado. Instituto de Química, UFRJ, Brasil, 1994.

43. Rodrigues, C. R., Alencastro, R. B. \& Barreiro, E. J. Resumos da $18^{\underline{a}}$ Reunião Anual da SBQ, SA-013, Minas Gerais, Brasil, 1995.

44. Albuquerque, M. G., Rodrigues, C. R., Alencastro, R. B. $\&$ Barreiro, E. B. $35^{\text {th }}$ Sanibel Symposium, Florida, USA, 1995.

45. Albuquerque, M. G., Rodrigues, C. R., Alencastro, R. B. \& Barreiro, E. B. Int. J. Quantum Chem., Quantum Biol. Symp. 1995, 22, 181.

46. Pereira, N. P. Tese de Mestrado, Instituto de Química, UFRJ, Brasil, 1994.

47. Cucurou, C., Battioni, J. P., Thang, D. C., Nam, N. H. \& Mansuy, D. Biochemistry 1991, 30, 8964.

48. Musser, J. H. \& Kreft, A. F. J. Med. Chem. 1992, 35, 2501.

49. Chasteen, N. D., Grady, K. J., Shorey, I. K., Neden, J. K., Riendeau, D. \& Percival, M. D. Biochemistry 1993, 32, 9763.

50. Schilstra, M. J., Veldink, G. A. \& Vliegenthart, F. G. Biochemistry 1994, 33, 3974.

51. van der Zee, J., Eling, T. E. \& Mason, R. P. Biochemistry 1989, 28, 8363 .

52. Bruneau, P. \& Delvare, C. J. Med. Chem. 1991, 34, 1028.

53. Cucurou, C., Battioni, J. P., Daniel, R. \& Mansuy, D. Biochem. Biophys. Acta 1991, 1081, 99.

54. Harrold, M. W., Grajzl, B., Shin, Y., Romstedt, K. J., Feller, D. R. \& Miller, D. D. J. Med. Chem. 1988, 31, 1506.

55. Hirata, M., Hayashi, Y., Ushikubi, F., Yokota, Y., Kageyama, R., Nakanishi, S. \& Narumiya, S. Nature 1991, $349,617$.

56. Yamamoto, Y., Kamiya, K. \& Terao, S. J. Med. Chem. 1993, 36, 820.

57. Fortier, S., Erman, M. G., Langs, D. A. \& DeTitta, G. T. Acta. Cryst. B 1980, 36, 1099.

58. Nos prostanóides, a cadeia que contém a função ácido carboxílico é denominada de cadeia a e a que contém a função hidroxila, de cadeia w.

59. Takasuka, M., Yamakawa, M. \& Watanabe, F. J. Chem. Soc. Perkin Trans. II 1989, 1173.

60. Takasuka, M., Kishi, M. \& Yamakawa, M. J. Med. Chem. 1994, 37, 47.

61. Ezumi, K., Yamakawa, M. \& Narisada, M. J. Med. Chem. 1990, 33, 1117.

62. Jin, B. \& Hopfinger, A. J. J. Chem. Inf. Comp. Sci. 1994, 34,1014
63. Albuquerque, M. G. Tese de Mestrado, Instituto de Química, UFRJ, Brasil, 1994.

64. Albuquerque, M.G., Alencastro, R. B. \& Barreiro, E. J. Resumos da $18^{\underline{a}}$ Reunião Anual da SBQ, SA-10, Minas Gerais, Brasil, 1995.

65. Demoupolos, C. A., Pinckard, R. N. \& Hanahan, D. J. J. Biol. Chem. 1979, 254, 9355.

66. Muirhead, E. E., Pitcock, J. A. Hypertens. J. 1985, 3, 1.

67. Prescott, S. M., Zimmerman, G. A. \& McIntyre, T. M. J. Biol. Chem. 1990, 265, 17381.

68. McManus, L. M., Pinckard, R. N., Fitzpatrick, F. A., O'Rourke, R. A., Crawford, M. H. \& Hanahan, D. J. Lab. Invest. 1981, 45, 303.

69. Whittaker, M. Curr. Op. Therap. Patents. 1992, $2,583$.

70. Hanahan, D. J., Demoupolos, C. A., Liehr, J. \& Pinckard, R. N. J. Biol. Chem. 1980, 255, 5514.

71. Godfroid, J. \& Braquet, P. Trends Pharm. Sci. 1986, 7, 368.

72. Chao, W. \& Olson, M. S. Biochem. J. 1993, 292, 617.

73. Nakamura, M., Honda, Z., Izumi, T., Sakanaka, C., Mutoh, H., Minami, M., Bito, H., Seyama, Y., Matsumoto, T., Noma, M. \& Shimizu, T. J. Biol. Chem. 1991, 266, 20400.

74. Dubost, J. P., Langlois, M. H., Audry, E., Braquet, P., Coletter, J. C., Croizet, F. \& Dallet, P. In: Braquet, P. (ed) CRC Handbook of PAF and PAF antagonists. CRC Press, Boca Raton, Florida, 1991, p261.

75. Godfroid, J., Dive, G., Lamotte-Brasseur, J., Batt, J. \& Heymans, F. Lipids 1991, 26, 1162.

76. Hodgkin, E. E. Miller, A. \& Whittaker, M. J. Comp.-Aided Mol. Design 1993, 7, 515.

77. Bures, M. G., Danaher, E., Delazzer, J. \& Martin, Y. C. J. Chem. Inf. Comput. Sci. 1994, 34, 218.

78. Sant'Anna, C. M. R., Alencastro, R. B., Fraga, C. A. M., Barreiro, E. J. \& Motta Neto, J. D. Int. J. Quantum Chem. 1996 (in press).

79. Sant'Anna, C. M. R., Motta Neto, J. D., Barreiro, E. J. \& Alencastro, R. B. $35^{\text {th }}$ Sanibel Symposium, Florida, USA, 1995.

80. Sant'Anna, C. M. R., Fraga, C. A. M., Alencastro, R. B. $\&$ Barreiro, E. J. Resumos da $18^{\underline{a}}$ Reunião Anual da $S B Q$, SA-019, Minas Gerais, Brasil, 1995.

81. Garcia, V. L. \& E. J. Barreiro, Abstracts of the 10th International Congress of Heterocyclic Chemistry, p. 8, Waterloo, Canadá, 1985.

82. Campbell, S. F. Química Nova 1991, 14, 196.

83. Miklavc, A., Kocjan, D., Mavri, J., Koller, J. \& Hadzi, D. Biochem. Pharm. 1990, 40, 663.

84. Wang, S., Milne, G. W. A., Nicklaus, M. C., Marquez, V. E., Lee, J. \& Blumberg, P. M., J. Med. Chem. 1994, 37, 1326.

85. Stewart, J. J. P. MOPAC version 6.00, Frank J. Seiler Research Laboratory, United States Air Force Academy, Colorado Springs, CO, 1990.

86. Broyden, C.G. J. Inst. Math. Its Appl. 1970, 6, 222.

87. Fletcher, R. Comp. J. 1970, 13, 317.

88. Goldfarb, D. Math. Comput. 1970, 24, 23.

89. Shanno, D. F. Math. Comput. 1970, 24, 647

90. Peçanha, E. P., Fraga, C. A. M. \& Barreiro, E. J. Resumos da $18^{a}$ Reunião Anual da SBQ, QO-014, Minas Gerais, Brasil, 1995.

91. Kubinyi, H. (ed) $3 D$ QSAR in drug design: theory, methods and applications. ESCOM, Leiden 1993.

92. Gallop, M. A., Barret, R. W., Dower, W. J., Fodor, S. P. A. \& Gordon, E. M. J. Med. Chem. 1994, 37, 1233.

93. Martin, E. J., Blaney, J. M., Siani, M. A., Spellmeyer, D. C., Wong, A. K. \& Moos, W. H. J. Med. Chem. 1995, 38, 1431.

94. Kubynyi, H., Pharmazie 1995, 50, 647. 